\title{
Implementation of 3D Printing Technology in the Food Industry
}

Nor Aiman Sukindar (Corresponding Author)

Manufacturing and Materials Department, Kulliyyah of Engineering, International Islamic University Malaysia, 53100 Gombak, Malaysia

Email: noraimansukindar@gmail.com

\section{Noorazizi Mohd Samsuddin}

Razak Faculty of Technology and Informatics, Level 6 Menara Razak, Universiti Teknologi Malaysia (UTM), Jalan Sultan Yahya Petra, 54100 Kuala Lumpur, Malaysia

Email: norazizi@utm.my

\section{Sharifah Imihezri Bt. Syed Shaharuddin}

Manufacturing and Materials Department, Kulliyyah of Engineering, International Islamic University Malaysia, 53100 Gombak, Malaysia

Email: shaimihezri@iium.edu.my

\section{Shafie Kamaruddin}

Manufacturing and Materials Department, Kulliyyah of Engineering, International Islamic University Malaysia, 53100 Gombak, Malaysia

Email: shafie@iium.edu.my.com

\begin{abstract}
Ahmad Zahirani Ahmad Azhar
Manufacturing and Materials Department, Kulliyyah of Engineering, International Islamic University Malaysia, 53100 Gombak, Malaysia

Email: zahirani@iium.edu.my.com
\end{abstract}

\section{Yang Chuan Choong}

Manufacturing and Materials Department, Kulliyyah of Engineering, International Islamic University Malaysia, 53100 Gombak, Malaysia

Email: yangcc@iium.edu.my.com

\section{Muhammad Adil Ab Wahab}

3Organic Gain Sdn Bhd, No. 6 \& 8, Jalan P/5, Seksyen 13, Kawasan Perindustrian Bangi, 43650 Bandar Baru Bangi, Selangor, Malaysia

Email: adilawi2@gmail.com

\begin{abstract}
This project involves the implementation of 3D printing technology on designing and fabricating food holders in the food industry. Food holders are designed to hold the food packages in the filling line for food manufacturing industries that apply retort technology. Therefore, this study aims to implement the 3D printing technology in particular FDM to fabricate food holders for the food processing industry. The approach of using this technology is focused on giving more view on the capability of 3D printing technology, aiming at reducing the overall process fabrication cost and fabrication time. Hence, the fabrication cost and time between FDM and conventional machining methods were compared. This study revealed that Organic Gain food industry was able to reduce the cost and fabrication time for the food holder up to approximately $96.3 \%$ and $72 \%$ respectively. This project gives an insight into the ability of 3D printing technology in delivering the demands of the industry in producing parts as well as the adaptability of the technology to the industry in new product development. The project was carried out successfully and the 3D printed food holder has been tested and functions smoothly.
\end{abstract}

Keywords: Fused deposition modeling; Food industry; 3D printing technology.

\section{Introduction}

The use of 3D printers is growing tremendously, and this technology's rapid growth shows promising potential. In general, 3D printing technology can be classified into many types such as binder jetting, directed energy deposition, material extrusion, material jetting, powder bed fusion, sheet lamination, and vat photopolymerization [1]. The general principles of 3D printing include 3D modeling, printing, and post-processing. 3D Modeling is where the analysing and collecting data is done to determine the shape and the appearances of the objects. After all the information is taken, a model is being designed using CAD software and finally saved in .STL format. Printing is a process where a 'slicer' software is used to convert the .STL file into G-code, and from the code, the 3D printing is executed. Next, post-processing such as support removal, polishing, gap/void filling, and spray painting takes place. This finishing will increase the surface quality and precision of the object [2]. 
Among the 3D printing technologies, fused deposition modeling (FDM) is the most widely used due to the low cost and flexibility of this technology [3, 4]. The working principle of FDM is quite simple where the material in the form of filament will be pushed by the motor through the extruder, melted, and deposited via the hot end layer by layer [5]. FDM technology can be used to print a variety of materials, making it a good alternative for the industry, especially for the fabrication process.

The low cost of the FDM process allows it to be utilized in large and small businesses. Many researchers are finding the impact of 3D printing on small businesses and suggest that small businesses should implement entrylevel 3D printing since it has lower cost and hands-on experience in 3D printing [6]. The 3D printing technology provides an opportunity with unrestricted design ability for the goods and can optimize the economic [7]. One of the industries implementing this technology is the food industry [8]. The 3D technologies that are relevant to be applied in the food printing industries include FDM, selective sintering technology, powder bed binder jetting, and ink-jet printing.

The present study aims to implement the 3D printing technology in particular FDM to fabricate food holders for the food processing industry. A food holder is a device used to hold the packaging pouch in the filling line and should be designed to cater to the varieties of food packaging sizes. The study then compares the fabrication cost and time between FDM and conventional machining methods.

\section{Material and Method}

The design and development of food holders using 3D printing technology (FDM) focused on two aspects. The first aspect was on the fabrication cost of the food holder and the second aspect is on the fabrication time. The fabrication time and cost using a 3D printer were compared to the conventional method of machining. Previously, the company fabricated the food holder using conventional machining which involved milling and drilling operations. In this study, the new approach using FDM technology was compared.

\subsection{Fabrication Cost}

The fabrication cost of the food holder will be compared by taking the cost for one unit using 3D printing and the conventional processing method. Organic Gain Sdn. Bhd food industry reported that the overall fabrication costs using the conventional machine were RM30,720. The overall production cost by the 3D printer was estimated by translating the weight-based cost to the time-based cost [9]. The material used for FDM printing was Polylactic acid (PLA) Plus which costs RM60/kg. A total of $16 \mathrm{~kg}$ of PLA Plus filaments were consumed to produce the food holders in this study. Below are the mass and printing time details for the fabrication of a single food holder unit:

- Printing time: $456 \mathrm{~min} / \mathrm{unit}$

- $\quad$ Mass : 200gm/unit

The 3D printing fabrication cost was estimated using Equation 1.

$$
\frac{\text { Weight single food holder }}{\text { printing time (min) }} \times \text { cost per gram }
$$

Fig. 1 shows the CAD design for the food holder used in the filling line for the production of retort food.

Figure-1. CAD design for food holder used in the filling line

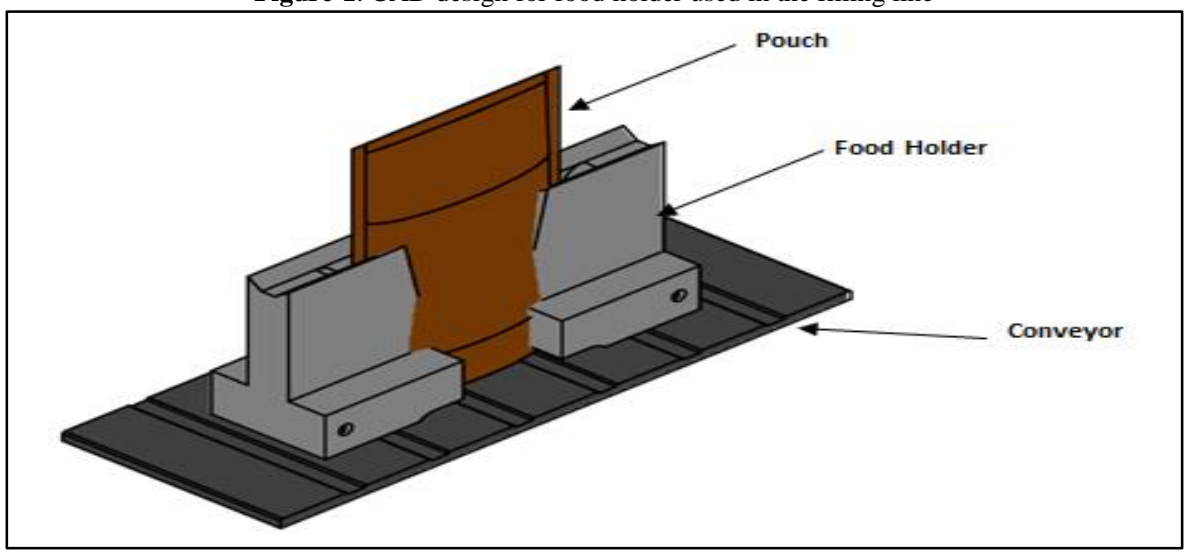

\subsection{Fabrication Time}

The overall manufacturing lead time using conventional machining process approximately took 3 months to be complete and delivered to the customer. This information was used and compared with the overall lead time using 3D printing technology. Generally, in this study, the fabrication time of 3D printing technology can be estimated by calculating the printing time. The printing time in this study was based on the optimum printing parameters. Table 1 shows the optimum printing parameters used to give maximum output for mass production. This project was carried out using three units of 3D printing machine Artillery Sidewinder X1. The 3D printing time was estimated using Equation 2.

$$
\mathrm{Ti}=\frac{\mathrm{Ai}}{\mathrm{vD}}+\mathrm{Tr}
$$


Where, $\mathrm{Ai}$ is area per layer to be printed, $\mathrm{Ti}$, is build time for one layer, $\mathrm{v}$ is the volume, $\mathrm{D}$ is the nozzle diameter and $\mathrm{Tr}$ is delay time.

Table-1. Printing parameter setup for 100gm food holder

\begin{tabular}{l|l}
\hline Printing parameters & Value \\
\hline Height layer & $0.12 \mathrm{~mm}$ \\
\hline Nozzle diameter & $0.4 \mathrm{~mm}$ \\
\hline Delay time & $81 \mathrm{~seconds}$ between each layer \\
\hline Printing Speed & $35 \mathrm{~mm} / \mathrm{s}$ \\
\hline Volume & $130080.81 \mathrm{~mm}^{3}$ \\
\hline Surface & $26830.12 \mathrm{~mm}^{2}$ \\
\hline Layers to complete & 318 \\
\hline
\end{tabular}

\section{Results}

In this section, the fabrication cost and fabrication time using conventional machining and 3D printing technology were compared. The estimation value can be taken as a guideline to compare between these two technologies specifically in the fabrication of food holders.

\subsection{Fabrication Cost}

The fabrication cost of the 3D printing was estimated using Equation 1. The cost is approximately RM1.60/hour of 3D printing time. Based on the printing time of a single food holder, the total cost is RM12.16. However, this is not representing the final cost. Some cost was also included to the initial cost such as labor and maintenance [9]. These costs were estimated at RM2.00/unit which led to the final total cost of RM14.16/unit. Hence, the overall cost of fabrication using 3D printing technology for 80 pieces was RM1132.80. Fabricating the same food holder design via a conventional machining process yielded a per-unit cost of RM384.00 and a total cost of RM RM30,720. Fig. 2 and 3 show the cost comparison for 1 piece of food holder and the total cost of the 80 pieces of food holder.

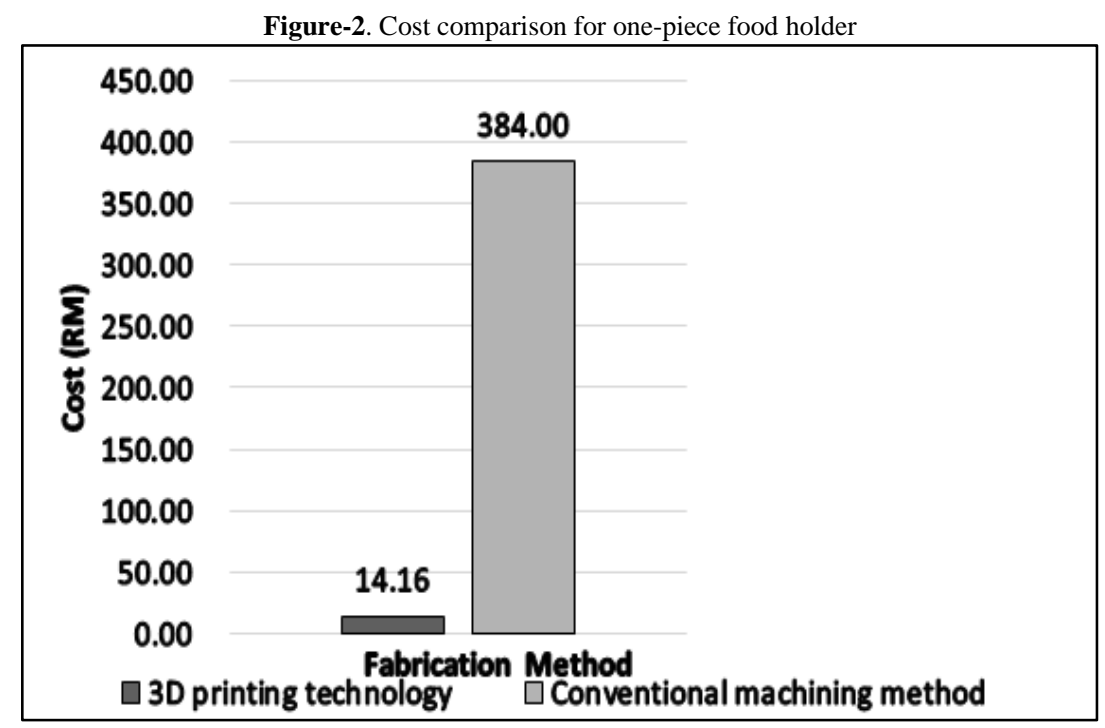

Figure-3. The total cost of fabrication comparison for food holder using 3D printing technology and conventional machining method

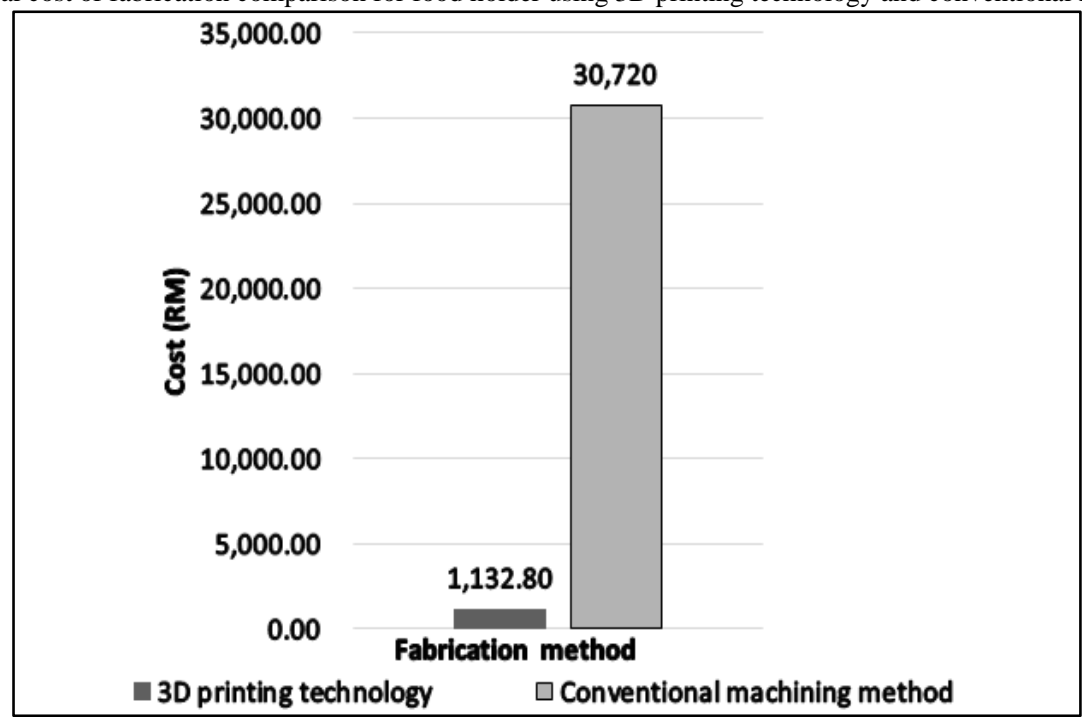




\subsection{Fabrication Time}

Fabrication time for 3D printing technology was estimated using Equation 2. Below shows, some calculations involved in estimating the fabrication time using 3D printing technology. The printing time for a $100 \mathrm{gm}$ food holder was calculated and approximately is 7.6 hours and for the 80 pieces is 608 hours. This project involves 3 units of 3D printer which mean the total fabrication time is 203 hours. Meanwhile, the total hours of fabrication using the conventional machining method (based on expected completion by the factory) is 720 hours. The total fabrication for 3D printing technology was compared with the conventional machining method as shown in Fig. 4 . Fig. 5 shows the final food holder printed using 3D printing technology used in the filling line.

Figure-4. Fabrication time comparison for food holder using 3D Printing Technology and Conventional Machining Method
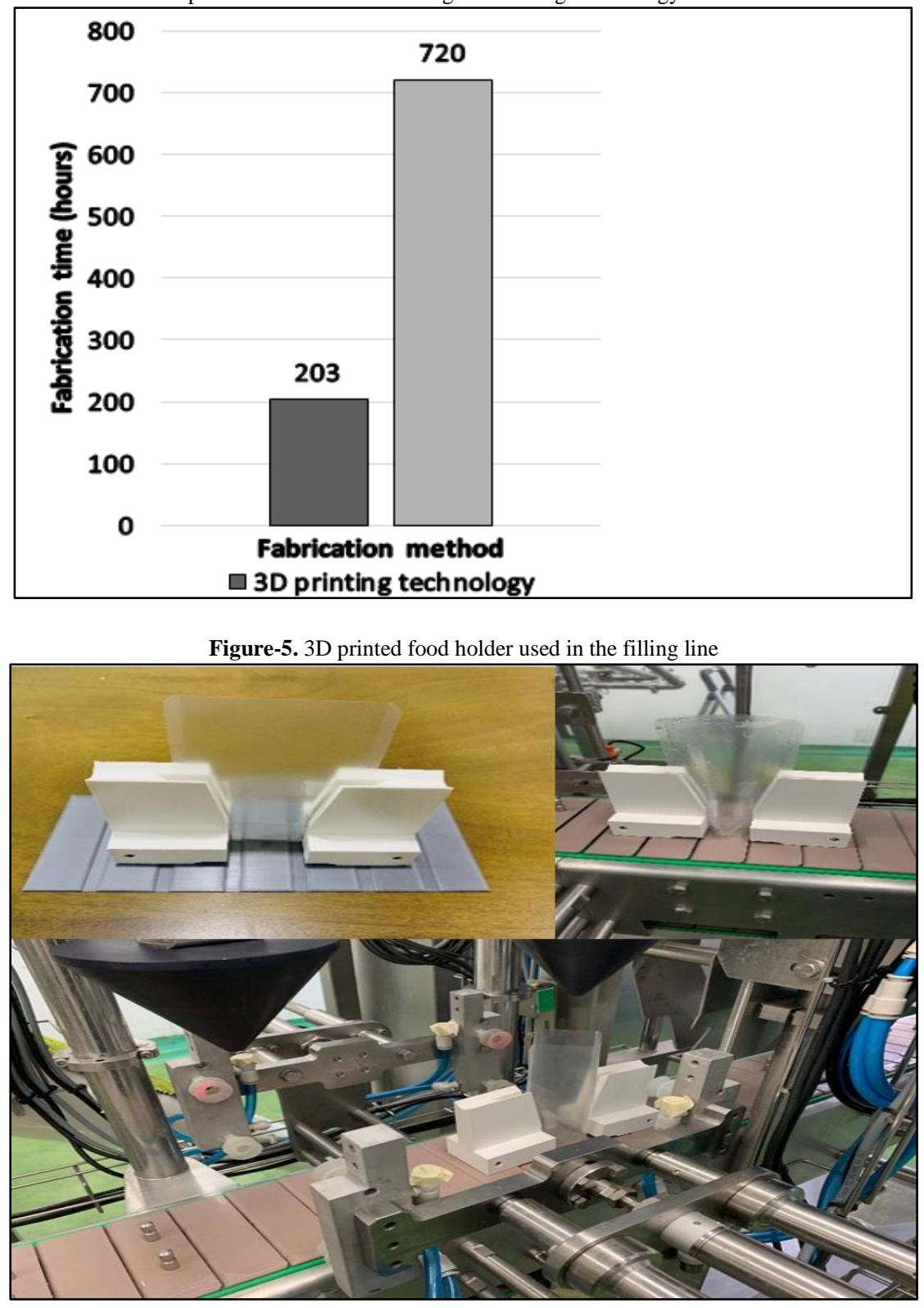

\section{Discussion}

In this study, the fabrication cost and time were evaluated for food holder used in the food assembly line of Organic Gain Sdn. Bhd. The fabrication cost in Figure 2 and 3, clearly shows that the company can reduce the cost of fabrication of food holders by $96.3 \%$. This shows that 3D printing technology has a massive impact on the cost reduction in fabrication. Some advantages of the $3 \mathrm{D}$ printing technology are the ability in printing a variety of materials to suit the application. In this study, Polylactic acid plus (PLA+) material has been used which suit to the application of food holder. The PLA+ is very common and suitable to be extruded using 3D printing technology especially using fused deposition modeling (FDM).

Fig. 4 shows that by using 3D printing technology, the company can save approximately $72 \%$ of fabrication time compared to the conventional machining method. High production efficiency resulting in $97 \%$ lead-time production using 3D printing in the industry has also been reported [10]. This finding aligns with the previous study that the 3D printing technology able to reduce production time [11]. The efficiency of this 3D printing technology leads to major differences in overall fabrication time. The ability to tweak the printing parameters using the slicer software based on the product design is a major advantage over the conventional machining method. For example, 
layer height can be tailored from $0.1 \mathrm{~mm}$ up to $0.4 \mathrm{~mm}$ thickness. If the product application does not require a highly smooth surface finish, a height layer in the range of $0.3 \mathrm{~mm}-0.4 \mathrm{~mm}$ can be used which helped to reduce the overall manufacturing time. Effective manufacturing time can also be achieved by tailoring the printing parameters such as infill density and shell thickness to the product's application.

\section{Conclusion}

This study compares the fabrication cost and time between 3D printing technology and conventional machining method for food holders. The results obtained show Organic Gain food industry was able to reduce the cost and fabrication time up to $96.3 \%$ and $72 \%$ respectively. The printing parameters can be tailored according to the needs and applications which contribute to this reduction in fabrication cost and time. This study shows that the 3D printing process particularly FDM can be used to aid the food industry to fabricate functional product applications in the production line. Overall, 3D printing technology is a viable fabrication alternative in the manufacturing industry and the market will continue to grow in the future.

\section{References}

[1] Lee, T. C., Ramlan, R., Shahrubudin, N., Lee, T. C., and Ramlan, R., 2019. "An overview on 3D printing technology: Technological, materials and technology: Applications technological, materials, an overview on 3d printing and applications." Procedia Manufacturing, vol. 35, pp. 1286-96.

[2] Gokhare and Vinod, G., 2017. "A review paper on 3d-printing aspects and various processes used in the 3dprinting." International Journal of Engineering Research and Technology, vol. 6, pp. 953-58.

[3] Dudek, P., 2015. "FDM 3d printing technology in manufacturing composite elements." Archives of Metallurgy and Materials, vol. 58, Available: DOI:10.2478/amm-2013-0186

[4] Turner, B. N., Robert, S., and Scott, A. G., 2014. "A review of melt extrusion additive manufacturing processes: I. Process design and modeling." Rapid Prototyping Journal, vol. 20, pp. 192-204.

[5] Mpofu, Thabiso, P., Cephas, M., and Macdonald, M., 2016. "The impact and application of 3D printing technology." International Journal of Science and Research, vol. 3.

[6] Conner, Brett, P., Guha, P., Manogharan, and Kerry, L. M., 2015. "An assessment of implementation of entry-level 3d printers from the perspective of small businesses." Rapid Prototyping Journal, vol. 5, pp. 582-97.

[7] Otcu, Gulsen, B., Lucia, R., and Sergio, T., 2019. "State of the art of sustainability in 3D food printing." IEEE International Conference on Engineering, Technology and Innovation, 978-1-7281-3401-7/18.

[8] Izdebska, J. and Zolek-Tryznowska, Z., 2016. "3D food printing-facts and future." Agro Food Industry Hi Tech, vol. 27, pp. 33-37.

[9] Kim, B., 2017. "How to price 3D printing service fees." Available: https://acrl.ala.org/techconnect/post/how-to-price-3d-printing-service-fees/

[10] Taylor, S., 2014. "3D printing industry." Available: https://3dprintingindustry.com/news/stratasys-whalecreate-97-lead-time-reduction-3d-printing-28060/

[11] Bowoto, Oluwole, Prince, N., and Ifeoluwa, E., 2019. "Reduction in economic cost and production time for development of a $3 \mathrm{~d}$ printer and its effect on market economic." International Journal of Engineering Trends and Technology, vol. 67, pp. 92-97. 